\title{
The Fusarium oxysporum Effector Six6 Contributes to Virulence and Suppresses I-2-Mediated Cell Death
}

\author{
F. Gawehns, P. M. Houterman, F. Ait Ichou, C. B. Michielse, M. Hijdra, B. J. C. Cornelissen, M. Rep, and \\ F. L. W. Takken \\ University of Amsterdam, Faculty of Science, SILS, Molecular Plant Pathology, Science Park 904, 1098 XH Amsterdam \\ Submitted 8 November 2013. Accepted 18 November 2013.
}

Plant pathogens secrete effectors to manipulate their host and facilitate colonization. Fusarium oxysporum f. sp. $l y$ copersici is the causal agent of Fusarium wilt disease in tomato. Upon infection, $F$. oxysporum f. sp. lycopersici secretes numerous small proteins into the xylem sap (Six proteins). Most Six proteins are unique to $F$. oxysporum, but Six6 is an exception; a homolog is also present in two Colletotrichum spp. SIX6 expression was found to require living host cells and a knockout of SIX6 in F. oxysporum f. sp. lycopersici compromised virulence, classifying it as a genuine effector. Heterologous expression of SIX6 did not affect growth of Agrobacterium tumefaciens in Nicotiana benthamiana leaves or susceptibility of Arabidopsis thaliana toward Verticillium dahliae, Pseudomonas syringae, or $F$. oxysporum, suggesting a specific function for $\boldsymbol{F}$. oxysporum f. sp. lycopersici Six6 in the F. oxysporum f. sp. lycopersicitomato pathosystem. Remarkably, Six6 was found to specifically suppress I-2-mediated cell death (I2CD) upon transient expression in $N$. benthamiana, whereas it did not compromise the activity of other cell-death-inducing genes. Still, this I2CD suppressing activity of Six6 does not allow the fungus to overcome $I-2$ resistance in tomato, suggesting that $I-2$-mediated resistance is independent from cell death.

Plants are challenged by a wide variety of microbes, including viruses, bacteria, fungi, and oomycetes (Agrios 1997). Thanks to their multilayered immune system, plants recognize and defeat most potential invaders (Jones and Dangl 2006). However, pathogenic microbes evolved various mechanisms that suppress plant immunity, resulting in disease (Win et al. 2012). Mostly, this disease-causing ability is mediated by secreted virulence factors-called effectors - that alter host-cell function or otherwise promote host colonization (Hogenhout et al. 2009). Therefore, identification and characterization of effectors provide insights into the mechanisms underlying susceptibility to pathogens.

Pathogenic strains of the fungus Fusarium oxysporum invade roots of a broad variety of plant species and cause wilt disease through colonization of the xylem vessels (Tjamos and Beckman 1989). Each strain can only infect one or a few closely

Corresponding author: F. L. W. Takken; E-mail: f.1.w.takken@uva.nl

* The $\boldsymbol{e}$-Xtra logo stands for "electronic extra" and indicates that three supplementary tables and two supplementary figures are published online and also that Figures 5, 6, and 7 appear in color online.

(C) 2014 The American Phytopathological Society related hosts, and strains infecting the same host are grouped into the same host-specific form or forma specialis (f. sp.) (Armstrong and Armstrong 1981; Katan 1999; Katan and Di Primo 1999). Thus far, most effectors have been identified from $F$. oxysporum strains infecting tomato and belonging to f. $\mathrm{sp}$. lycopersici. The first $F$. oxysporum f. sp. lycopersici effectors that have been identified are proteins encoded by avirulence (AVR) genes; namely Avr1, Avr2, and Avr3 (Houterman et al. 2008, 2009; Rep et al. 2004). Avr proteins trigger host resistance upon recognition by corresponding resistance $(\mathrm{R})$ proteins in plants. Hence, $F$. oxysporum f. sp. lycopersici is divided into three races named after the corresponding $R$ gene that recognizes the Avr protein. Functional analyses revealed that Avr2 and Avr3 trigger resistance in tomato plants carrying the $R$ genes $I-2$ and $I-3$, respectively (Rep et al. 2004; Houterman et al. 2009). In addition to triggering resistance, both proteins are required for full pathogenicity on susceptible tomato lines (Houterman et al. 2009; Rep et al. 2005), classifying them as genuine effectors. $F$. oxysporum f. sp. lycopersici effector Avr1, recognized by $I$ and $I-1$, does not contribute to virulence on susceptible cultivars but suppresses I-2- and I-3-mediated resistance (Houterman et al. 2008). All three Avr proteins were originally identified in the xylem sap of $F$. oxysporum f. sp. $l y$ copersici-infected tomato plants (Houterman et al. 2007). In addition to the Avr proteins, 11 other secreted-in-xylem (Six) proteins have been identified thus far; all are relatively small ( $<300$ amino acids [aa]), generally cysteine rich, and produced with a signal peptide for secretion (Houterman et al. 2007; Lievens et al. 2009; Ma et al. 2010; Schmidt et al. 2013). Six proteins generally do not have sequence homology to proteins with known functions (Rep 2005), prohibiting reliable prediction and assignment of specific functions to these proteins. Expression of at least some $S I X$ genes (e.g., AVR3, SIX2, AVR2, and $S I X 5)$ is regulated by the transcription factor Sge1; a knockout of the gene encoding this regulator impairs pathogenicity of the fungus and abolishes SIX gene expression (Michielse et al. 2009). Analysis of the $F$. oxysporum f. sp. lycopersici genome revealed that most SIX genes are localized on chromosome 14 (Ma et al. 2010; Schmidt et al. 2013). This lineagespecific chromosome is required for infection of tomato and can be shuttled via horizontal transfer from $F$. oxysporum f. sp. lycopersici to a nonpathogenic strain, converting this strain into a tomato pathogen ( $\mathrm{Ma}$ et al. 2010). This highlights the importance of the SIX gene-carrying chromosome for the ability of the fungus to cause disease. Until now, Avr2 and Six 5 have exclusively been found in F. oxysporum f. sp. lycopersici, suggestive of a tomato-specific function for these two effectors. For other Six proteins, such as Avr1, Six6, Six7, Six8, and Six9, close homologs are present in other formae speciales (Chakrabarti et al. 2011; Lievens et al. 2009; Thatcher et al. 
2012), implying a more generic function for these proteins. Among these, Six6 is of special interest because homologs are also present in two other fungal plant pathogens, Colletotrichum orbiculare and C. higginsianum (Gan et al. 2013; Kleemann et al. 2012).

Here, we describe the functional characterization of $F$. oxysporum f. sp. lycopersici Six6 and show that it is a genuine effector protein important for pathogenicity.

\section{RESULTS}

\section{F. oxysporum f. sp. lycopersici Six6 homologs are present in several formae speciales of $\boldsymbol{F}$. oxysporum and in two Colletotrichum spp.}

Upon infection, F. oxysporum f. sp. lycopersici secretes Six6 into the xylem sap of tomato (Lievens et al. 2009). The Six6 precursor is encoded by a gene spanning 648 bp (GenBank accession ACY39286.1). SignalP 4.0 (Petersen et al. 2011) predicts a 16-aa signal peptide yielding a mature protein of 199 aa. Six6 contains seven cysteines and has a predicted molecular weight of $22 \mathrm{kDa}$ (ProtParam) (Wilkins et al. 1999). National Center for Biotechnology Information BLAST searches did not reveal hits to proteins with known functions (data not shown) but uncovered the presence of Six6 in other F. oxysporum formae speciales. In total, six Six6 homologs were identified in F. oxysporum ff. spp. melonis (ACY39292.1), niveum (ADO60274.1), radicis-cucumerinum (ACY39291.1), passiflorae (ADO60275.1), vasinfectum (ADO60273.1), and cubense (Chakrabarti et al. 2011; Lievens et al. 2009; Schmidt et al. 2013; our unpublished observations), respectively. The amino acid sequences of $F$. oxysporum ff. spp. melonis, niveum, and radicis-cucumerinum Six6 are identical while the others diverge (Fig. 1). F. oxysporum f. sp. passiflorae Six6 shows the highest similarity with $F$. oxysporum f. sp. lycopersici Six6, having $93 \%$ sequence identity at the protein level. Six6 of $F$. oxysporum ff. spp. melonis and vasinfectum share 90 and $89 \%$ sequence conservation, respectively, with $F$. oxysporum f. sp. lycopersici Six6. The most distantly related Six6 is that of $F$. oxysporum f. sp. cubense, having $60 \%$ identity. The number of nonconservative amino acid substitutions is overall very low (e.g., between F. oxysporum f. sp. lycopersici and F. oxysporum f. sp. melonis Six6, there is only one nonconservative change, Asn to Leu).

Outside the $F$. oxysporum species complex, Six6 homologs were found in C. higginsianum, called ChEC36, and in C. orbiculare. ChEC36 is 9 a longer than the Six6 homologs from $F$. oxysporum and has $38 \%$ protein sequence identity with $F$. oxysporum f. sp. lycopersici Six6. The Six6-like $C$. orbiculare protein is 223 aa long and shares $57 \%$ identity with $F$. oxysporum f. sp. lycopersici Six6. Alignment of the six Six6 homologs (Fig. 1) shows that the N-terminal half of the mature protein is less conserved than the $\mathrm{C}$-terminal half (10 versus $33 \%$ ). In the C-terminal half, three conserved motifs (ExCVx

1..... Signal peptide …...।

\begin{tabular}{|c|c|c|c|c|c|c|}
\hline & & & & & & \\
\hline Six6 & MKLALIASIL AAGCVAGPLA & QTE-SESADV & AEHTINYIDI & APEEFEPLKA & -NLSSLVSRD & TLPDHTCF \\
\hline & MKLALIASIL AAGCVAGPLA & QTE-PESADV & AEHTINYIDI & APEEFEPPKA & -DLSSLVSRD & TLPVTNCP \\
\hline & MKLALIASIL & QTE-SESADV & AEHTINYIDI & APEEFF & -NLSSLVSRD & TLP \\
\hline & MKVALVISIF & PAKTPTSPPG & AEHTLNYVDI & TPTGPI & NG & TLPH \\
\hline & -MFSLLVXIL & QVEDSATKLL & LDVAPVELDV & ALAVHEPLNT & TSLAIIGF & ARTNPPC \\
\hline & KELTVV & EVDGS-GNSI & PTVELSPVDG & PPAEIEPLNA & -NLTSLVARD & TGPDRT \\
\hline
\end{tabular}

71

\begin{tabular}{|c|c|c|c|c|c|c|c|}
\hline & & & & & & & \\
\hline . & YK & ANTIR & NPRSNREKIT & & NGKS & IPIVDL & VE \\
\hline & DRSVCYK & ANTIRSFCVA & NPRSNREKIS & KPQEIC & SNGKS & IPVVDL & VQ \\
\hline ix6 & YDESICIT & AGVVRSSCVF & TADPGVRRGV & NKNEIC & NGKR & YAKCIPIAHL & $\mathrm{VE}$ \\
\hline & QTYDRSVCYN & SHTIR & NPRSNREQIT & GEVC & SGKS & DL & VST \\
\hline & SICYT & SGIISRYCNT & VPQSPNGDRK & EVFCANNEV & ILLSNGKP & FADCQLISSL & QWRTD \\
\hline & VCYK & YNTIR & PRSNREDIK & TPCRAD & NLSNGKS & FAQCIELVKL & IRW \\
\hline
\end{tabular}

141

\begin{tabular}{|c|c|c|c|c|c|c|c|}
\hline $\mathrm{Si}$ & TTTSVN & $\overline{\text { PAGY }}$ & $\overline{\text { II }}$ & SYFGEP & EGIGGS & TSYFSSDNFQ & RY \\
\hline $\mathrm{S}$ & :TTTSVN & PAGY & $I$ & FGEP & GGS & DNFQ & रY \\
\hline & TTTSVN & PAGYHHLGTI & DV & [SYFGEP & GNVNEGIGGS & TSYFSSD & F \\
\hline & ITTSVN & PAGNF & VYDV & SYFGEP & EGIGGS & TSYFSSN & $Y$ \\
\hline & $\mathrm{KEC}$ & PIG & IYDI & LGEP & GDANEGI & VSNFSSDRFR & NY \\
\hline & SK & THA & VYDI & KYFGEP & PKGTSGT & TNNFASESWD & FDNGHFM \\
\hline & $\mathrm{N}$ & $\mathrm{im}$ & & IRYLGE & I & SYFNSDF & $\mathrm{GH}$ \\
\hline
\end{tabular}

211

Fol Six6

Fom* $\operatorname{Six} 6$

Fov Six6

FoC Six6

ChEC36

Co Six6

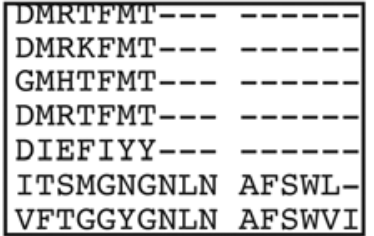

Fig. 1. Six6 homologs carry conserved motifs in their C-terminal part. Alignment of Fusarium oxysporum f. sp. lycopersici Six6 and Six6 homologs from F. oxysporum and two Colletotrichum spp. The signal peptide sequence predicted by Signal P is depicted, conserved amino acids are highlighted, and conserved motifs are underlined. Fol $=$ F. oxysporum f. sp. lycopersici, Fop $=F$. oxysporum f. sp. passiflorae, Fom $=$ F. oxysporum f. sp. melonis, Fov $=F$. oxysporum f. sp. vasinfectum, Foc $=$ F. oxysporum f. sp. cubense, ChEC36 = Colletotrichum higginsianum, and Co $=$ C. orbiculare. Fom*: because Six 6 sequences of $F$. oxysporum ff. spp. melonis, niveum, and radicis-cucumerinum are identical, only the $F$. oxysporum $\mathrm{f}$. sp. melonis sequence is shown. 
RxLSxGK, GxxEGCT, and TxxYDxNxxPIxVxKIxYxGEPG) can be discerned.

In summary, Six6 is relatively widespread and well conserved within the F. oxysporum complex. Furthermore, homologs are present in C. higginsianum and in C. orbiculare.

\section{SIX6 is expressed during early stages}

of $\boldsymbol{F}$. oxysporum $\mathrm{f}$. sp. lycopersici infection.

Six6 was originally identified in xylem sap of 7-week-old tomato plants 2.5 weeks after infection with $F$. oxysporum $\mathrm{f}$. sp. lycopersici (Houterman et al. 2007; Lievens et al. 2009). To determine whether SIX6 is also expressed during earlier stages of infection, RNA was collected from $F$. oxysporum f. sp. $l y$ copersici-infected tomato seedlings 4, 8, and 12 days postinoculation (dpi). Expression of SIX6 was monitored using reverse-transcriptase polymerase chain reaction (RT-PCR) and a SIX6 transcript could be detected at all selected time points in infected plants but not in mock-inoculated controls (Fig. 2A). Expression of SIX6 was not detected in F. oxysporum $\mathrm{f}$. sp. lycopersici mycelium when grown in synthetic medium but the transcript was found when grown in the presence of suspension-cultured tomato cells (Fig. 2B). In conclusion, SIX6 is expressed at early and late stages of host infection and its expression requires the presence of living host cells.

\section{SIX6 knockouts of $F$. oxysporum f. sp. lycopersici show reduced virulence.}

To determine the role of Six6 in virulence, SIX6 knockout mutants were generated in $F$. oxysporum $\mathrm{f}$. sp. lycopersici by replacing SIX6 with a hygromycin resistance cassette. PCRbased screening of 92 hygromycin-resistant transformants identified 23 transformants that had undergone an in locus recombination resulting in deletion of the SIX6 gene.

Six independent SIX6 knockout strains were selected for further analysis. To assess a possible contribution of SIX6 to virulence, 10-day-old susceptible tomato seedlings were inoculated with either i) the SIX6 knockout strains, ii) two inde-
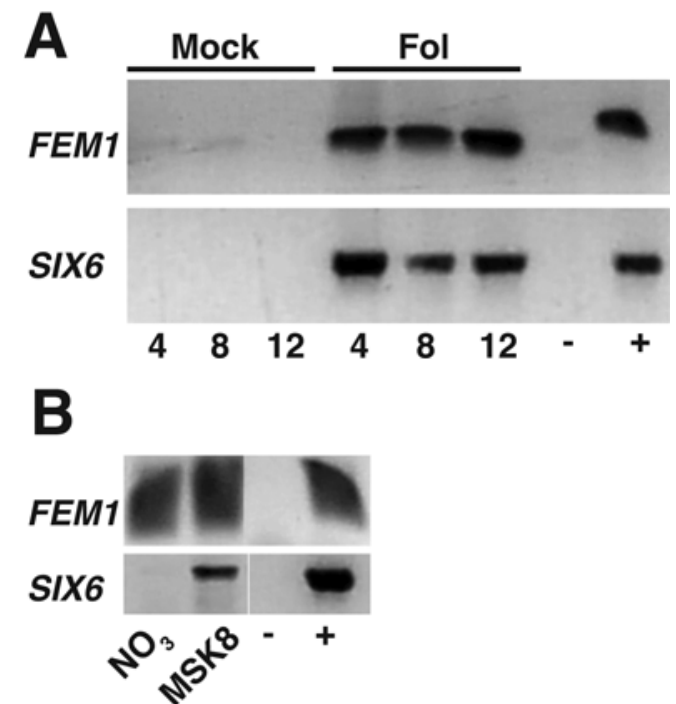

Fig. 2. SIX6 is expressed during early and late stages of infection and its expression is triggered by living host cells. Reverse-transcriptase polymerase chain reaction analysis of SIX6 or FEM1 expression using RNA isolated from A, roots of tomato seedlings, which were either mock or Fusarium oxysporum f. sp. lycopersici inoculated and harvested 4, 8, and 12 days after inoculation; or $\mathbf{B}$, F. oxysporum f. sp. lycopersici cultivated in either synthetic $\left(\mathrm{NO}_{3}\right)$ medium or in the presence of suspension cultured tomato (MSK8) cells. Water was included as a negative control (-), while genomic DNA of F. oxysporum f. sp. lycopersici (+) and its FEM1 gene were used as positive controls. pendent ectopic transformants not having a SIX6 gene deletion, iii) wild-type F. oxysporum f. sp. lycopersici (Fol007, race 2) or iv) water, to serve as a mock control. Three weeks after inoculation, plant weight and disease index were measured. The disease index (Rep et al. 2004) was scored on a scale from 0 to 4,
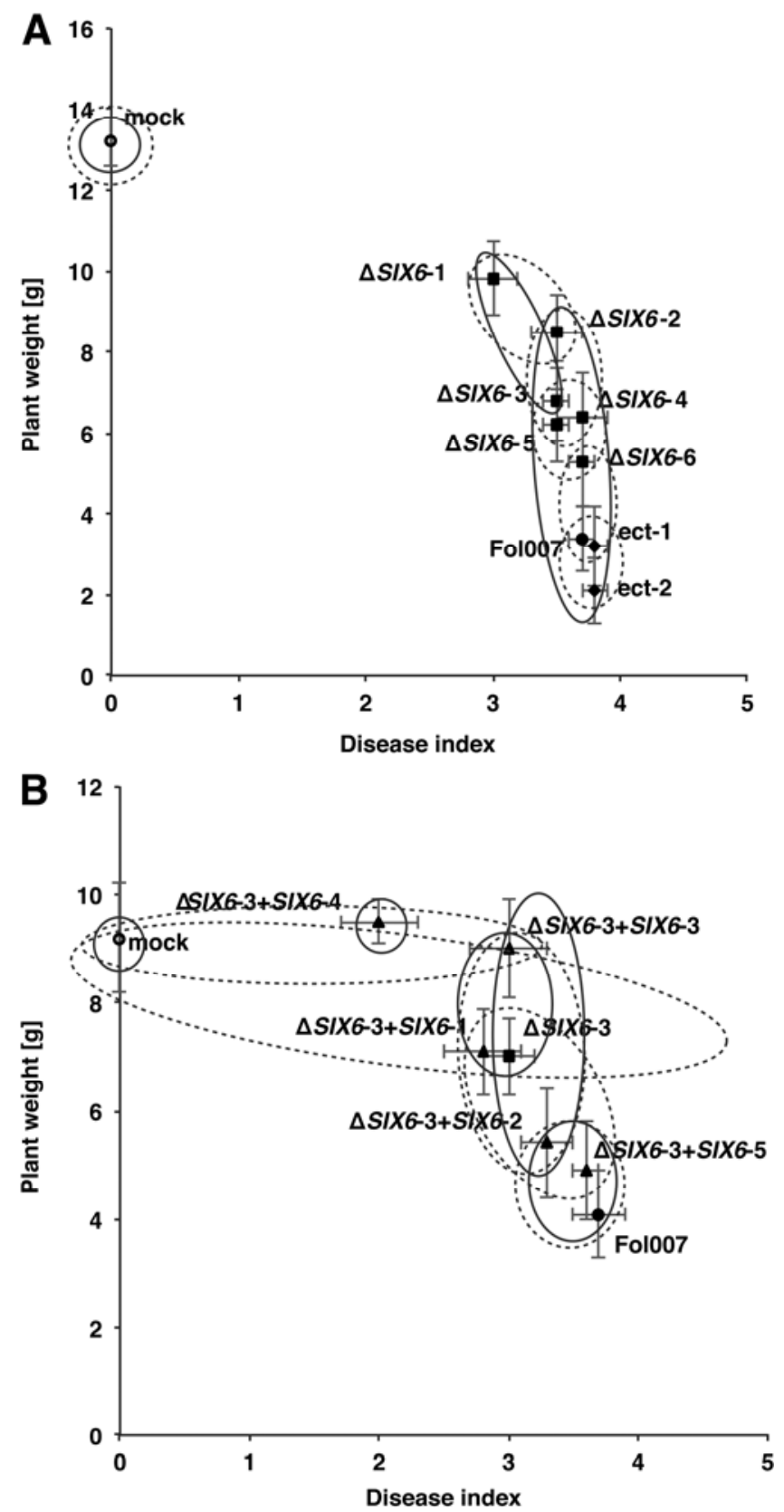

Fig. 3. Fusarium oxysporum f. sp. lycopersici SIX6 knockout mutants are reduced in virulence. Susceptible tomato seedlings were inoculated with wild-type F. oxysporum f. sp. lycopersici (Fol007), strains in which SIX6 was deleted ( $\triangle S I X 6$ numbers 1 to 6$)$, or a knockout strain $(\triangle S I X 6-3)$ in which SIX6 was reintroduced ( $\triangle S I X 6-3+S I X 6-1$ to SIX6-5). As a control, mock-inoculated plants were used (mock), and two transformants (ect), in which the SIX6 deletion construct was integrated ectopically. A, Average plant weight of 20 plants is plotted against the average disease index of the same plants. Deletion of SIX6 impairs pathogenicity as shown by the increased plant weight compared with infection with the wild type or the two ectopic transformants. B, Two of the five independent knockout strains carrying the SIX6 complementation construct display a similar average disease index and plant weight as the $F$. oxysporum f. sp. lycopersici wild type. Error bars represent the standard error. Clustering is based on an analysis of variance (Fisher's protected least significant difference significant at 95\%) using either the disease index (solid line) or plant weight (dashed line). 
with 0 having no symptoms (no wilting, no brown vessels) and 4 being either dead or small and wilted (Supplementary Fig. $\mathrm{S} 1$ shows representative examples of the disease classes). The disease index plotted against the plant weight of the $F$. oxysporum f. sp. lycopersici bioassay in a dot plot is shown in Figure $3 \mathrm{~A}$. The different treatments are clustered based on significant differences in diseases index (solid lines) or plant weight (dotted lines). Significant differences between the groups were determined in an analysis of variance (ANOVA) using Fisher's protected least significant difference (PLSD) at $95 \%$, resulting in three distinct classes for the disease index and five for weight (Supplementary Table S1). All SIX6 knockout strains exhibited a significant increase in plant weight compared with the wild-type Fol007 or the ectopic controls (Fig. 3A), indicating a reduction in fungal virulence. Surprisingly, however, a significant reduction in disease index was only observed for two of the six SIX6 knockout strains ( $\triangle S I X 6$ 1 and $\triangle$ SIX6-3 knockouts).

To ascertain that the reduced virulence of the mutants was indeed caused by loss of SIX6, mutant $\triangle S I X 6-3$ was transformed with a SIX6 complementation construct. PCR confirmed the presence of an ectopically inserted construct in five transformants and virulence of these strains was assessed using bioassays. One transformant $(\triangle S I X 6-3+S I X 6-4)$ showed fewer disease symptoms than the SIX6-3 knockout. This impairment in virulence was possibly due to a mutation caused by the ectopic insertion of the SIX6 construct or an unlinked mutation due to the transformation procedure. Statistical analysis (ANOVA with PLSD at $95 \%)$ showed that two transformants ( $\triangle S I X 6-3+$ SIX6-1 and $\triangle S I X 6-3+S I X 6-3)$ cluster together with the SIX6 knockout with regard to the disease index and plant weight, indicating no complementation of virulence (Fig. 3B). However, in the two other SIX6 transformants $(\triangle S I X 6-3+S I X 6-2$ and $\triangle S I X 6-3+S I X 6-5)$, pathogenicity was fully restored. These two complementants cluster with the wild-type Fol007 and have both a high disease index and a strong reduction in plant weight, confirming full restoration of virulence (Fig. 3B). Hence, the reduction in virulence of the SIX6 knockout can be functionally complemented using an ectopically expressed SIX6 gene.

To analyze the expression of SIX6 in the SIX6-3 knockout and the derived complementants, RT-PCR was performed on RNA isolated from roots of infected tomato seedlings (Fig. 4). To assess the presence of fungal RNA, confirming successful F. oxysporum f. sp. lycopersici infection, FEMI was used as a positive control. An FEM1 transcript was detected in cDNA from all inoculations except for the mock control. Notably, the intensity of the FEMI bands varied for the respective comple- mentation lines and, in general, the strains exhibiting the strongest increase in plant weight $(\triangle S I X 6-3$ and $\triangle S I X 6-3+$ SIX6-4) showed the lowest amount of FEMI amplification product, indicative for a lower abundance of the fungus in these infected plants. Next, expression of SIX6 was analyzed, and a SIX6 amplification product was found for wild-type Fol007 and all SIX6 complementants (Fig. 4) but not for the $\triangle$ SIX6-3 strain, further confirming that it is a genuine knockout. Because the control without reverse transcriptase (-RTase) did not show a SIX6 amplification product, it can be excluded that the bands originate from contaminating genomic DNA. In conclusion, because deletion of SIX6 impairs $F$. oxysporum $\mathrm{f}$. sp. lycopersici pathogenicity, which can be restored by ectopic complementation, SIX6 can be considered a genuine $F$. oxysporum f. sp. lycopersici effector gene.

\section{Six6 does not enhance virulence of Agrobacterium tumefaciens in Nicotiana benthamiana or alter susceptibility to Verticillium dahliae or $\boldsymbol{F}$. oxysporum in Arabidopsis thaliana.}

To test whether the virulence-promoting activity of Six6 extends to pathogens other than $F$. oxysporum f. sp. lycopersici, its ability to enhance virulence of a bacterial pathogen was assessed. The disarmed Agrobacterium tumefaciens strain GV3101 was transformed either with a binary vector encoding solely a tandem affinity purification (TAPi) tag, or with the same vector carrying a C-terminal TAPi-tagged SIX6. The sequence encoding the endogenous signal peptide of Six6 was removed (dSPSIX6) to enforce a cytosolic localization of the protein. As a positive control, the Pseudomonas syringae effector gene AvrPto was used. When AvrPto was expressed in Nicotiana benthamiana leaves using A. tumefaciens, its bacterial growth was increased (Hann and Rathjen 2007).

When grown in liquid culture, no growth differences were found between $A$. tumefaciens carrying the empty TAPi binary vector or vectors containing SIX6 or AvrPto (data not shown), showing that the mere presence of these transgenes did not affect bacterial growth. In planta growth of the transformed bacteria was monitored at two time-points after infiltration in $N$. benthamiana leaves (Fig. 5A). A. tumefaciens containing the empty TAPi vector typically grew $1 \log \mathrm{CFU} \mathrm{cm}{ }^{-2}$ in 4 days. Expression of SIX6 did not alter growth of A. tumefaciens in planta; the SIX6 transformants grew at the same rate and to the same titer as the empty vector control $(1 \log$ CFU $\mathrm{cm}^{-2} / 2$ days) (Fig. 5A). The positive control, A. tumefaciens carrying AvrPto, grew both faster and to higher titers, $>2 \log$

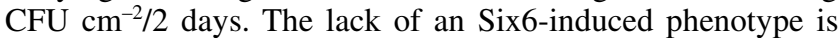
not due to the lack of SIX6 expression because the protein

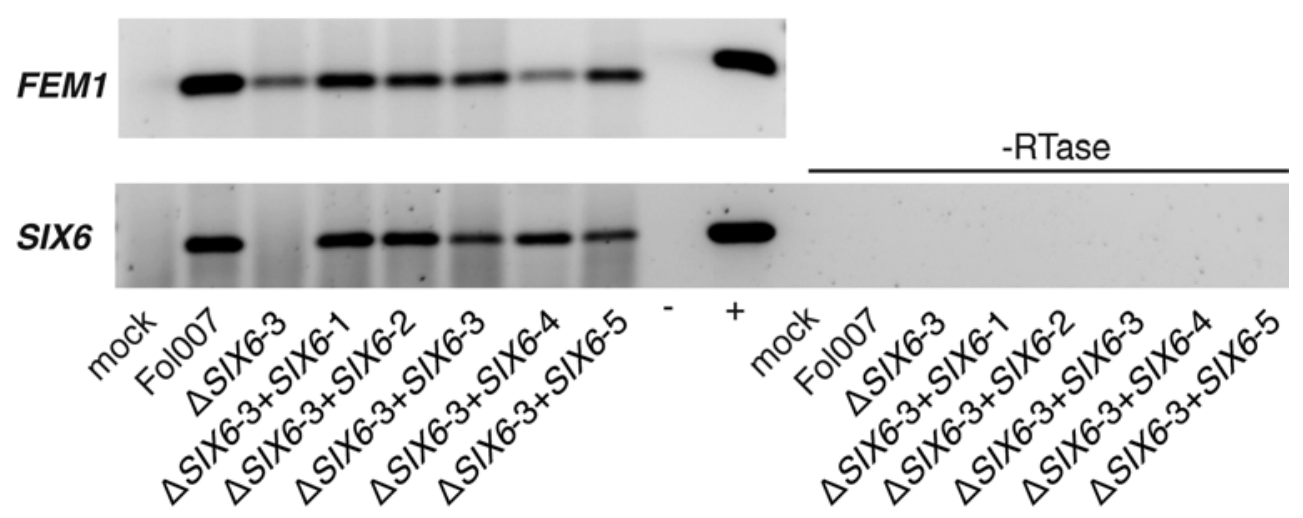

Fig. 4. SIX6-complemented SIX6 Fusarium oxysporum f. sp. lycopersici knockouts express SIX6 during plant infection. Reverse-transcriptase polymerase chain reaction analysis of SIX6 and FEM1 using RNA isolated from roots of 10-day-old seedlings inoculated with Fol007, the $\triangle$ SIX6-3 knockout-mutant, or one of the five knockout strains complemented with SIX6. Mock-inoculated seedlings and water were included as a negative control (-) while genomic DNA of F. oxysporum f. sp. lycopersici (+) and its FEMI gene were used as positive controls. 
could readily be detected on a Western blot probed with a PAP antibody recognizing the TAPi tag fused to Six6 (Fig. 6B). Hence, Six6 does not promote growth of A. tumefaciens in $N$. benthamiana.

To test whether Six6 alters susceptibility to other plant pathogens, stably transformed Arabidopsis thaliana Col-0 plants were generated expressing SIX6. Expression of the SIX6 gene was driven by the $35 \mathrm{~S}$ promoter and, to aid detection of the Six6 protein, it was fused to a TAPi tag. Two independent transgenic lines (Six6-1 and Six6-2) containing a single insertion of the 35S::dSPSIX6-TAPi construct were selected for analysis. The SIX6-overexpressing lines did not exhibit morphological aberrations or show a phenotype distinct from nontransformed Arabidopsis when grown under standard conditions (Fig. 5B,
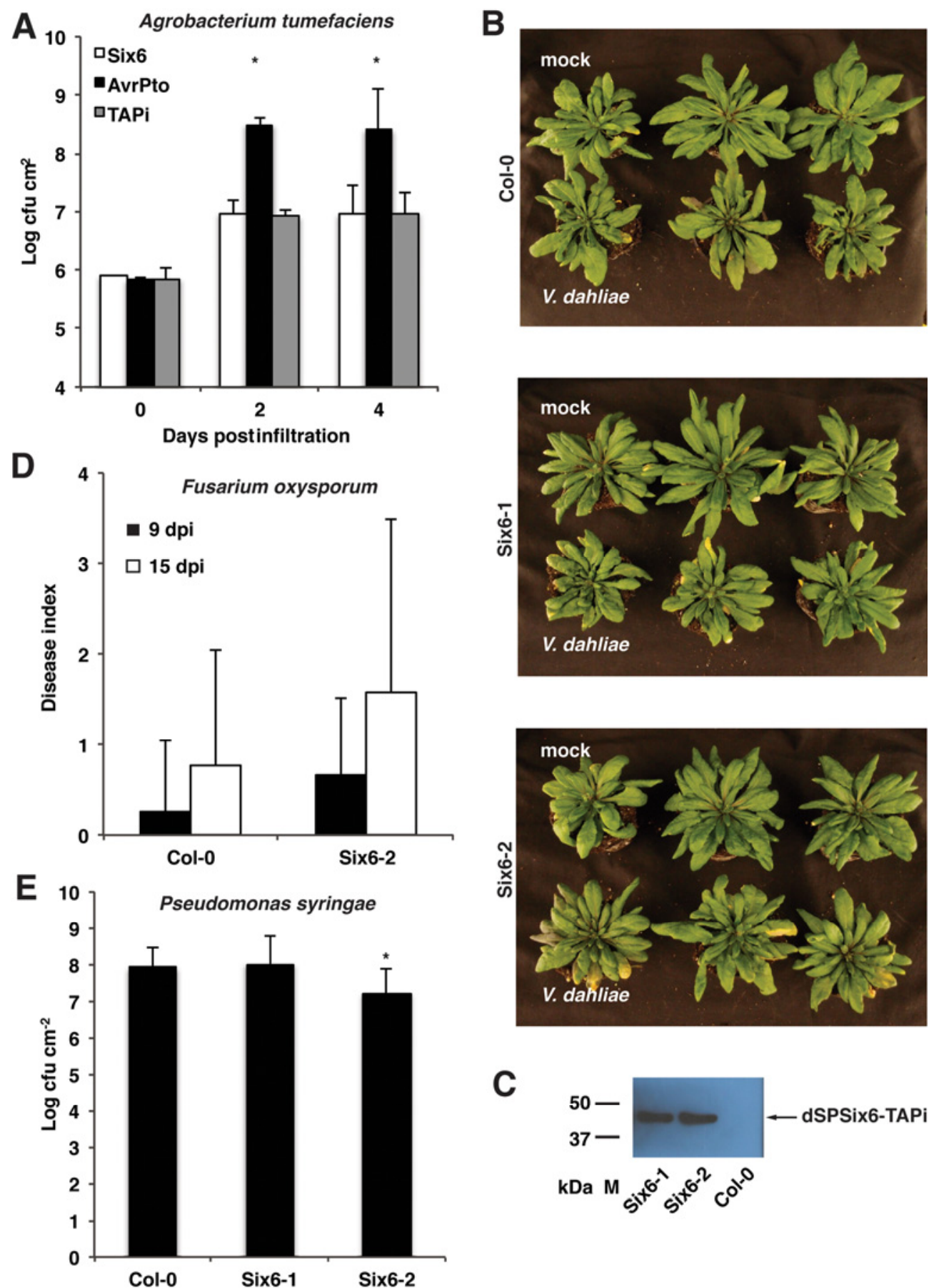

Fig. 5. SIX6 does not alter growth of Agrobacterium tumefaciens in Nicotiana benthamiana or susceptibility to Verticillium dahliae, Fusarium oxysporum, or Pseudomonas syringae. A, In planta growth of A. tumefaciens carrying SIX6, a positive control (AvrPto), or an empty vector (tandem affinity purification [TAPi]). Samples were taken 0, 2, or 4 days after $N$. benthamiana leaf infiltration (dpi). Bacterial growth of the empty vector control and SIX6 did not differ, whereas the bacterial titer was significantly higher in the AvrPto control. Bars indicate standard deviation of three replicates; * indicates significant difference between TAPi and AvrPto in a student $t$ test $(2 \mathrm{dpi}, P=0.0006 ; 4 \mathrm{dpi}, P=0.02)$. B, D, and E, Bioassays were performed on Col-0 and two independent Col-0 35S::dSPSIX6TAPi (Six6-1 and Six6-2) transformants. B, Photographs showing disease development (chlorosis and slightly reduced stature) of three representative plants 23 days after mock (upper rows) or $V$. dahliae inoculation (lower rows). C, Western blot showing the presence of the TAPi-tagged Six6 protein in Arabidopsis thaliana leaf protein extracts of the Six6 transformants. Detection was done using the PAP antibody. M = protein marker. D, Disease index scored at 9 and 15 days after $F$. oxysporum inoculation. Bars indicate standard deviation of 24 replicates. E, Bacterial growth of $P$. syringae 3 dpi. Bars indicate standard deviation of eight replicates; * indicates significant difference between the wild-type Col-0 and the Six6-2 transformant in a student $t$ test $(P=0.02)$. 
compare top panels). Accumulation of the Six6 protein in the two transformants was confirmed by Western blotting (Fig. 5C). Six6 is present in many F. oxysporum strains (Fig. 1) but not in the Arabidopsis-infecting strain Fo5176 (Thatcher et al. 2012). Hence, this strain was used to assess a potential change in disease susceptibility to $F$. oxysporum in Arabidopsis due to expression of SIX6. Thirteen-day-old seedlings were infected with Fo5176 and disease index was scored on a scale from 0 to 5 , in which 0 means that no disease symptoms developed and 5 that plants are dead (Supplementary Table S2) at either 9 or 15 dpi (Fig. 5D). No significant difference $(P>0.05)$ between disease symptoms on wild-type Col-0 and Col-0 35S::dSPSIX6$T A P i$ was observed, leading us to conclude that Six6 does not alter susceptibility of the plant to this strain of $F$. oxysporum.

To assess a potential contribution of Six6 to susceptibility of Arabidopsis toward another wilt-causing fungus, bioassays were performed using Verticillium dahliae. Twenty 1-day-old wildtype plants and the two SIX6-expressing $A$. thaliana lines were inoculated with $V$. dahliae spores and disease symptoms where scored 23 dpi (Fig. 5B). The amount of chlorosis was scored (discussed below) as a measure to quantify disease symptoms.
Disease symptoms were relatively weak and Six6 did not enhance or reduce symptom development on A. thaliana (Fig. 5B).

Finally, in planta growth of the plant-pathogenic bacterium $P$. syringae DC3000 was analyzed. Twenty 2-day-old A. thaliana plants were syringe infiltrated with $P$. syringae and leaf discs were collected from the infiltrated area at 3 dpi. A small but significant, decrease in bacterial growth was observed $(<1$ $\log$ CFU cm $\mathrm{cm}^{-2}$ ) in the 35S::dSPSIX6-TAPi line Six6-2 compared with the untransformed line but no difference was observed in line Six6-1 (Fig. 5E).

In summary, transient SIX6 expression does not increase susceptibility of $N$. benthamiana to Agrobacterium tumefaciens, nor does SIX6 expression in Arabidopsis thaliana enhance susceptibility to Fo5176 or V. dahliae. Furthermore, susceptibility of $A$. thaliana toward $P$. syringae was not consistently affected by expression of SIX6.

\section{Six6 suppresses I-2-mediated cell death.}

Many effectors enhance virulence of a pathogen by suppressing cell death, a response that often accompanies plant defense (Guo et al. 2009; Stassen and Van den Ackerveken
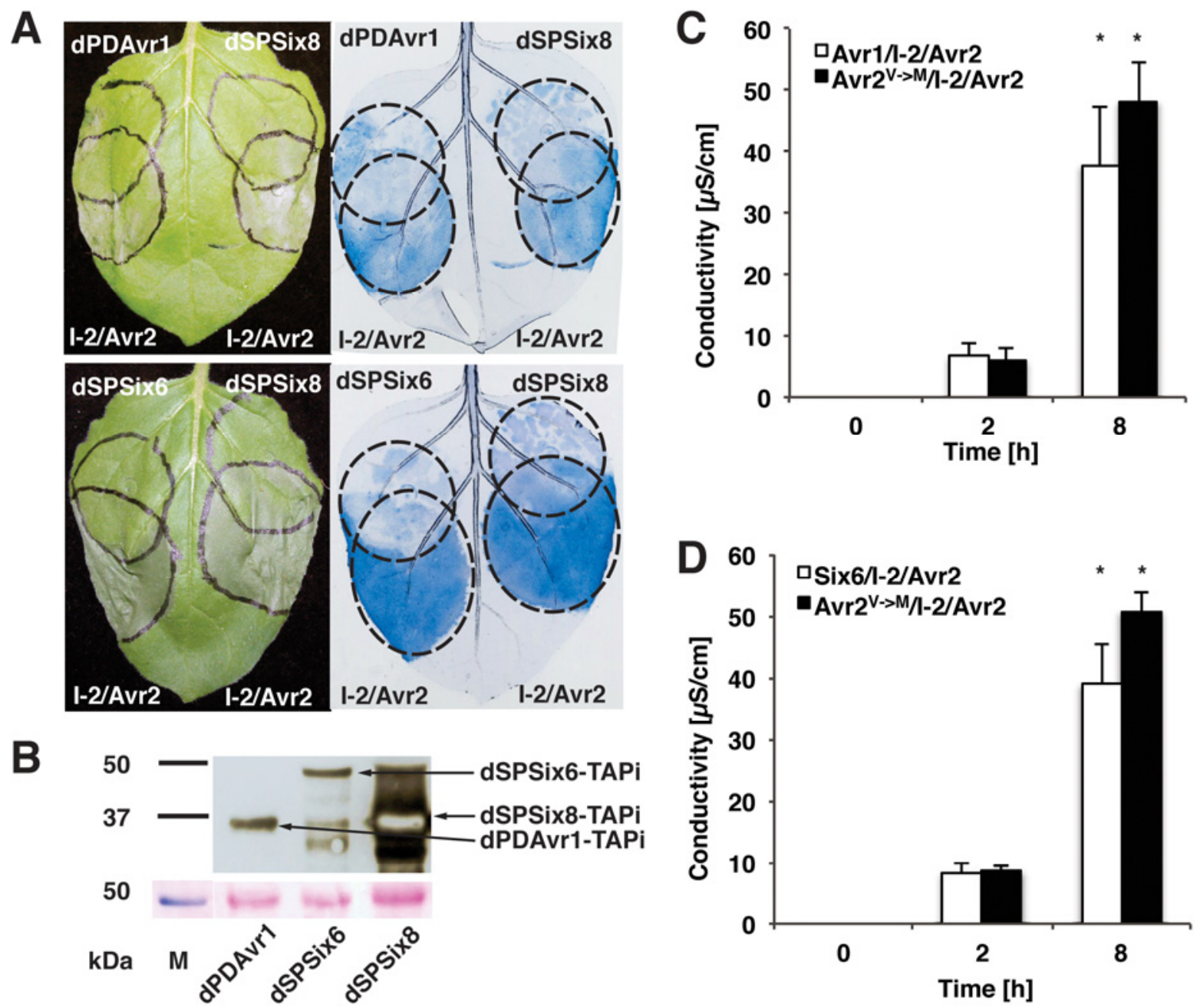

Fig. 6. Six6 suppresses I-2-mediated cell death and ion leakage. Co-expression of AVR1, SIX6, and SIX8 with AVR2 and I-2. A, Pictures of Nicotiana benthamiana leaves taken $48 \mathrm{~h}$ after infiltration (hpi) (left panel) and visualization of cell death with trypan blue staining (right panel). Lower circle: agroinfiltration of $I-2$ and $A V R 2$, upper circle: agroinfiltration of AVRI, SIX6, and SIX8 respectively. Effect on I-2-mediated cell death was scored in the overlap of the circles. B, Accumulation of Avr1, Six6, and Six8 shown using a Western blot probed with the PAP antibody (all Six proteins carry a tandem affinity purification [TAPi] tag). Arrows indicate the expected position of the Avr1-, Six6-, and Six8-TAPi fusion proteins. Ponceau S staining shows equal loading; M = protein marker. Conductivity of $N$. benthamiana leaf discs sampled from infiltrated leaf areas co-expressing $\mathbf{C}, I-2, A V R 2$, and AVR1 or D, I-2, AVR2, and SIX6. Leaf discs were collected at $26 \mathrm{hpi}$ and conductivity was monitored at 0,2 , and $8 \mathrm{~h}$ after harvesting and compared with that of $I-2-$, AVR2-, and $A v r 2^{\mathrm{V} \rightarrow \mathrm{M}}-$ expressing regions present on the same leaf. Bars represent standard deviation of five replicates; * indicates a significant difference between the $A v r 2^{\mathrm{V} \rightarrow \mathrm{M}}$ control and AVRI $(P=0.04)$ or SIX6 $(P=0.002)$ in a student $t$ test 
2011). To test whether Six6 can interfere with cell death, the SIX6 gene was co-expressed with a set of cell-death-inducing genes using agroinfiltration in $N$. benthamiana leaves. Because many $\mathrm{R}$ proteins can trigger cell death, representative members from different $R$ gene families were selected. Four distinct solanaceae $R$ genes ( $R x$, Pto, $C f 4$, and $I-2$ ) that confer resistance to a viral, a bacterial and two fungal pathogens, respectively, were selected for analysis (Table 1). Co-expression of these $R$ genes with their corresponding $A V R$ genes triggers a cell death reaction generally referred to as a hypersensitive response (HR). As a positive control for a cell death suppression assay, we tested whether F. oxysporum f. sp. lycopersici Avr1 can be used. We reported before that $F$. oxysporum f. sp. lycopersici Avr1 suppresses I-2-mediated resistance of tomato (Houterman et al. 2008). To test whether Avr1 can suppress I-2mediated cell death (I2CD), the I-2 gene was co-expressed with an $A V R l$ construct that lacks its signal peptide and prodomain (dPDAVRl) to assure that both proteins co-localize in the cytosol. The suppressing effect of Avr1 on I2CD is compared with the effect of Six8, a F. oxysporum f. sp. lycopersici Six protein with a size similar to Avr1 and Six6, in Figure 6A. In contrast to Six8, Avr1 was found to suppress cell death and reduce necrosis of the overlapping area. To better visualize the contrast between the living green cells and the dead brown cells, the dead cells were stained with trypan blue. The region where $A V R I$ - and I-2/AVR2-expression overlaps showed a slightly reduced blue staining compared with the Six 8 control (Fig. 6A, right panel). This is not due to a lack of expression because Western Blot analysis shows accumulation of Six8 and the other two effectors (Fig. 6B). Therefore, in addition to its suppressive effect on I-2-mediated resistance, Avr1 also suppresses I2CD, which makes it a proper positive control for a cell-death-suppression assay.

Notably, SIX6 infiltration reduced I2CD to an even larger extent than Avr1, as exemplified by the reduced trypan blue staining (Fig. 6A, lower panel). Because the SIX6 construct does not carry the sequence encoding the signal peptide (dSPSIX6), this implies that the Six6-mediated suppression of the I2CD occurs inside the plant cell. Its cell-death-suppressive effect was exclusively observed for I-2 because Rx-, Pto-, and Cf4-mediated HR were unaffected by Six6 (Table 1). Next, we analyzed whether Six6 can also suppress programmed cell death (PCD) induced by non- $R$ genes. INF1, encoding a $P h y$ tophthora infestans elicitor, and Bax, encoding a mammalian protein inducing apoptopic cell death (APC), were co-agroinfiltrated with SIX6. No cell-death suppression was observed in either case (Table 1) (data not shown). In summary, Six6, like Avr1, suppresses cell death triggered by the R protein I-2. Interestingly, this effect seems to be I-2 specific because cell death induced by other genes was unaffected by SIX6 co-expression.

\section{Six6 suppresses ion leakage accompanying I2CD.}

Visual scoring of cell death is semiquantitative. To measure cell death more quantitatively, ion leakage was measured, because it is known to accompany cell death (Coll et al. 2011).
SIX6, AVR1, or SIX8 were co-expressed with $A V R 2$ and I-2 using agroinfiltration in $N$. benthamiana. At $26 \mathrm{~h}$ postinfiltration (hpi), leaf discs were collected from the infiltrated area. These discs were transferred to water and conductivity of the solution was recorded for up to $12 \mathrm{~h}$. For the first $10 \mathrm{~h}$, the conductivity curves were highly reproducible but, at later time points, variation increased (data not shown). Therefore, two representative time points, 2 and $8 \mathrm{~h}$ after sampling, were selected, and these are depicted in Figure 6C and D. As negative control, an Avr2 variant $\left(A v r 2^{\mathrm{V} \rightarrow \mathrm{M}}\right)$ (Houterman et al. 2009) was used that is not recognized by I-2. Co-expression of $A v r 2^{\mathrm{V} \rightarrow \mathrm{M}}$ with $I-2$ and $A V R 2$ resulted in an identical conductivity curve as co-expression of $S I X 8$, validating its use as a negative control (Supplementary Fig. S2).

At $8 \mathrm{~h}$ after sampling, the $A V R l$-infiltrated leaf discs showed a significantly $(P=0.04)$ lower conductivity than the $A v r 2^{\mathrm{V} \rightarrow \mathrm{M}}$ control, which is in line with its ability to suppress I2CD (Fig. 6C). Conductivity in the SIX6-infiltrated discs was also significantly reduced at this time point compared with the $A v r 2^{\mathrm{V} \rightarrow \mathrm{M}}$ control $(P=0.002)$ (Fig. 6D). Hence, cell-death suppression by Avr1 and Six6 is accompanied by a significant suppression of I2CD-mediated ion leakage.

\section{Six6-GFP is present in cell cytoplasm and nucleus.}

Determining the subcellular localization of a protein can provide insight into the processes it affects. Hence, the SIX6 gene without the sequence encoding the signal peptide (dSPSIX6) was fused to green fluorescent protein $(G F P)$ and expressed in $N$. benthamiana leaves by agroinfiltration. As a reference, $G F P$ alone was expressed using the same vector. The integrity of the Six6-GFP fusion after agroexpression was confirmed by Western blot analysis (Fig. 7C). At 2 dpi, leaves were harvested and fluorescence was visualized using confocal microscopy. In epidermal cells expressing solely GFP, green fluorescence was observed at equal intensities in the cytoplasm and nucleus (Fig. 7B). Expression of dSPSIX6-GFP also resulted in green fluorescence in both the cytoplasm and the nucleus; however, in this case, fluorescence appeared stronger in the nucleus than in the cytoplasm, suggesting a nuclear preference for the Six6-GFP fusion protein (Fig. 7A, $\times 2$ magnification).

In conclusion, upon agroinfiltration, Six6-GFP localizes in both the nucleus and in the cytoplasm, suggesting that it is freely diffusible and is not tethered to a membrane or localized in a specific organelle.

\section{DISCUSSION}

F. oxysporum f. sp. lycopersici effectors differ in their distribution within the $F$. oxysporum species complex. Whereas some are highly F. oxysporum f. sp. lycopersici specific, others are also found in other formae speciales. Six 6 is not only present in other formae speciales of F. oxysporum but two homologs are also present in $C$. higginsianum and $C$. orbiculare. The Six6 homologs in the $F$. oxysporum complex are more related to F. oxysporum f. sp. lycopersici Six6 than the ones from

Table 1. Overview of cell death-inducing proteins tested in the Six6 suppression assay

\begin{tabular}{|c|c|c|c|c|c|c|}
\hline $\begin{array}{l}\text { Cell death- } \\
\text { triggering protein }\end{array}$ & Donor organism & $\begin{array}{c}\text { Protein } \\
\text { class }^{\mathrm{a}}\end{array}$ & Conferring resistance to & $\begin{array}{l}\text { Recognition } \\
\text { of }\end{array}$ & $\begin{array}{l}\text { Type of cell } \\
\text { death }^{\mathbf{b}}\end{array}$ & $\begin{array}{c}\text { Suppression } \\
\text { by Six6 }\end{array}$ \\
\hline I2 & Tomato & $\mathrm{CNL}$ & Fusarium oxysporum f. sp. lycopersici & Avr2 & HR & Yes \\
\hline Rx & Potato & $\mathrm{CNL}$ & Potato virus $X$ & $\mathrm{CP}$ & HR & No \\
\hline Pto & Potato & CNL & Pseudomonas syringae & AvrPto & HR & No \\
\hline $\mathrm{Cf} 4$ & Tomato & RLP & Cladosporium fulvum & Avr4 & HR & No \\
\hline Inf1 & Phytophthora infestans & Elicitor & $\ldots$ & $\ldots$ & PCD & No \\
\hline Bax & Mouse & Elicitor & $\ldots$ & $\ldots$ & $\mathrm{CD}$ & No \\
\hline
\end{tabular}

${ }^{\mathrm{a}} \mathrm{CNL}=$ coiled-coil nucleotide-binding leucine-rich repeat protein and RLP $=$ receptor-like protein.

${ }^{\mathrm{b}} \mathrm{HR}=$ hypersensitive response, $\mathrm{PCD}=$ programmed cell death, and $\mathrm{ACD}=$ apoptopic cell death. 
C. higginsianum and C. orbiculare. This might reflect independent evolution of the gene in the genera Colletotrichum and Fusarium after speciation. However, because Six6 is not found in other Fusarium or Colletotrichum spp. or in other genera, another possibility is that SIX6 was exchanged between Colletotrichum spp. and $F$. oxysporum after speciation by horizontal gene transfer and then evolved at different rates within the respective fungal species. If so, transfer did not occur recently because their Six6 sequences have considerably diverged. Despite the relatively low conservation of Six6 between the two genera, three conserved C-terminal motifs can be discerned. These motifs might represent regions with conserved structural or biochemical functions and are good targets for future structural and functional analysis.

SIX6 is expressed in planta during infection and is essential for full virulence of $F$. oxysporum f. sp. lycopersici. Rather surprisingly, deletion of SIX6 merely affected plant weight but not the disease index of infected tomato plants. Clearly, the SIX6 knockout still has the capacity to cause severe vessel browning when evaluated 3 weeks after infection. The high residual plant weight suggests that the infection process is slower, allowing the plant to continue to grow during early stages of infection. This interpretation is supported by the observation that plant weight is highest for plants inoculated with strains
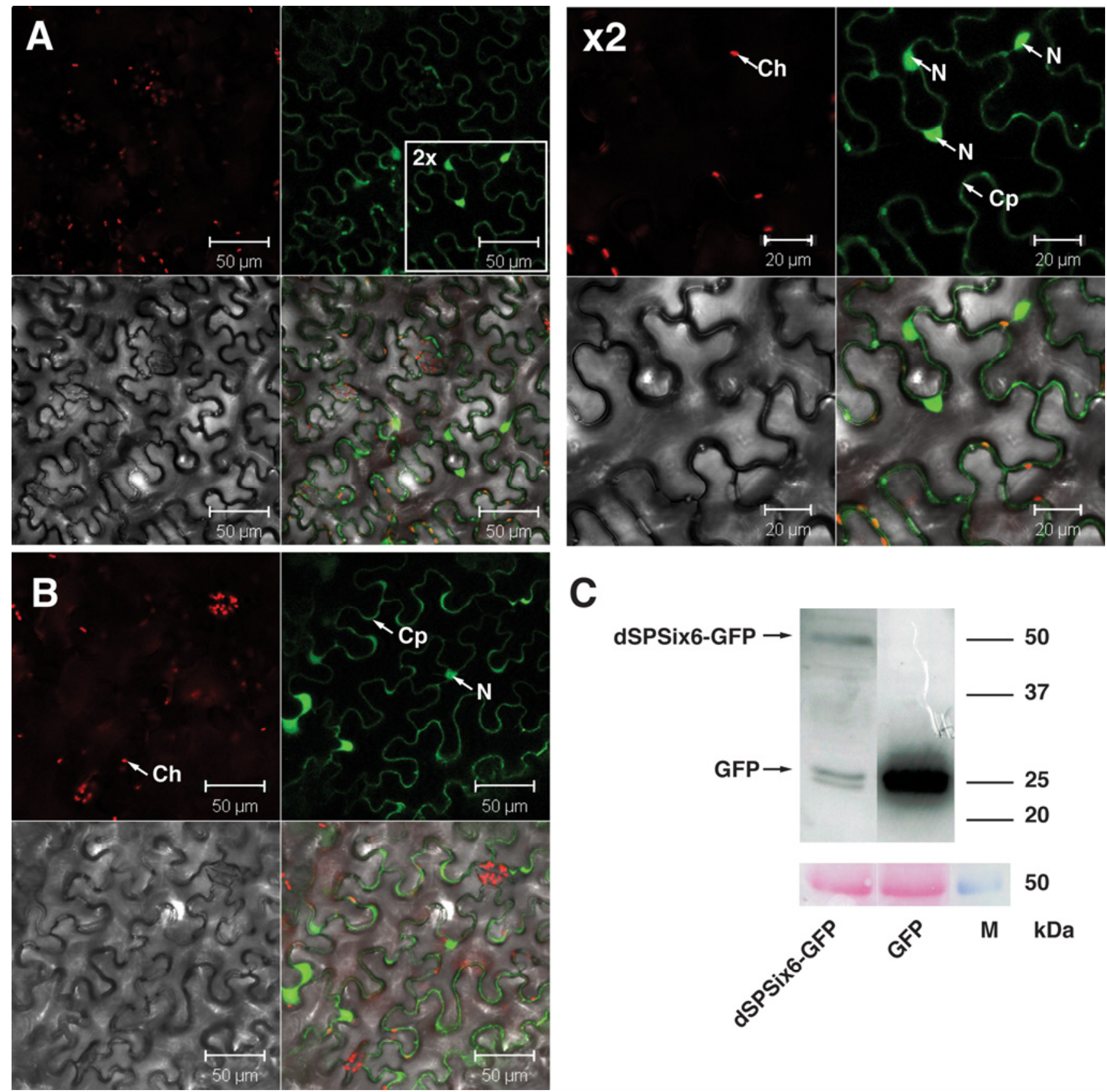

C

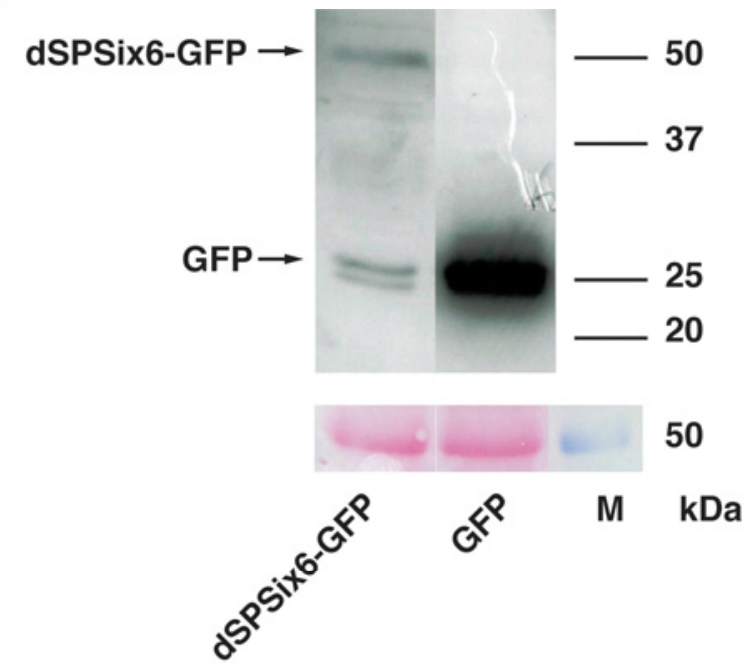

Fig. 7. Six6-green fluorescent protein (GFP) is localized in the cytoplasm and cell nucleus in Nicotiana benthamiana leaves upon agroinfiltration. Confocal image of leaves agroinfiltrated with A, dSPSIX6-GFP (left and right at a $\times 2$ magnification) or B, GFP alone. Fluorescence in the leaf epidermal cells was determined $24 \mathrm{~h}$ after infiltration (hpi) with confocal microscopy using an excitation wavelength of $488 \mathrm{~nm}$ and a $\times 40$ magnification. Each panel consists of a picture taken with a 650-nm-long path filter (upper left) for plant autofluorescence; and a 520- to 550-nm-band path filter (upper right) for GFP, transmitted light (lower left), and a stack of all three pictures (lower right). Arrows indicate different cell organelles $(\mathrm{Cp}=$ cytoplasm, $\mathrm{N}=\mathrm{nucleus}$, and $\mathrm{Ch}=\mathrm{chloro}-$ plast). C, Correct size of the fusion proteins was confirmed by Western blotting of leaf protein extracts using an anti-GFP antibody. Ponceau S staining as loading control. $\mathrm{M}$ = protein marker. 
$\Delta S I X 6-3$ and $\triangle S I X 6-3+S I X 6-4$, that have a relatively low amount of fungal biomass based on their FEM1 expression (Fig. 4). Remarkably, all F. oxysporum f. sp. lycopersici effector mutants analyzed thus far (AVR1, AVR2, AVR3, and SIX6) are compromised in virulence, which implies limited redundancy among $F$. oxysporum f. sp. lycopersici effectors. This notion corresponds with the relatively small number of candidate effector genes encoded on the pathogenicity chromosome $(n=16)$ and the limited number of candidate effector proteins found in the xylem sap $(n=14)$ (Houterman et al. 2007; Lievens et al. 2009; Ma et al. 2010; Schmidt et al. 2013).

Although Six6 is a virulence factor for $F$. oxysporum f. sp. lycopersici, transient expression of SIX6 did not affect growth of the bacterium Agrobacterium tumefaciens. Also, stable expression of SIX6 in Arabidopsis thaliana did not alter its susceptibility to the plant-pathogenic bacterium $P$. syringae or to the fungal pathogens $V$. dahliae and $F$. oxysporum. This result could be explained by the presumptive Six6 host target being i) not present in this plant species, ii) not present in the cytosol, or iii) not required for susceptibility to the aforementioned pathogens. Alternatively, iv) these pathogens might carry effectors whose activity is similar to that of Six6, concealing the effect of the expression of this gene. Because no Six6 homologs are present in Fo5176, P. syringae, or V. dahliae, such effectors would then not be related at the sequence level. We favor the fourth option because we found Six6 to be conserved in $F$. oxysporum strains infecting diverse hosts such as melon, banana, cotton, cucumber, watermelon, and passion fruit. The gene is also present in $C$. higginsianum that infects $A$. thaliana, and $C$. orbiculare, which causes disease in cucumber and melon, making alternative i unlikely. An argument to reject ii comes from our suppression assays, in which cytosolic Six6 was found to suppress I2CD in $N$. benthamiana. Hence, at least the Six6 target involved in I2CD disturbance must be present intracellularly in $N$. benthamiana. Interestingly, suppression of I2CD seems to be a specific feature of the Six6-target, because no suppression of cell death was found when SIX6 was co-expressed with other $R-A V R$ gene pairs, INF1, or the cell-death-inducing protein Bax (Table 1). This finding is surprising because, in agroinfiltration assays, cell-death-suppressing effectors typically act more broadly, as exemplified by AvrPtoB, HopPtoE, and HopPtoF from $P$. syringae, suppressing cell death accompanying both HR and APC (Abramovitch et al. 2006; Jamir et al. 2004). Also, Phytophthora infestans and $P$. sojae effectors suppress various types of cell death such as APC, PCD, and HR mediated by different R proteins (Dou et al. 2008; Gilroy et al. 2011; Kelley et al. 2010; Wang et al. 2011). In addition to effectors from bacteria and oomycetes, SPRYSEC-19, an effector of the nematode Globodera rostochiensis, also suppresses cell death mediated by several coiledcoil nucleotide-binding leucine-rich repeat immune receptors (Postma et al. 2012). To our knowledge, only the effector CgDN3 from $C$. orbiculare suppresses specifically only one form of cell death: the one mediated by the secreted protein NIS1 (Yoshino et al. 2012). Possibly, Six6 is a weak suppressor, and I2CD may be relatively easy to suppress because I-2mediated resistance to the $A V R 2$-carrying $F$. oxysporum f. sp. lycopersici strain typically does not involve HR (Beckmann 2000). The I2CD observed in $N$. benthamiana might be an anomaly due to overexpression of $I 2-A V R 2$ in this heterologous system, resulting in a cell death response, which may be easier to suppress than that induced by $R$ genes that do rely on HR for their function (Thomma et al. 2011).

With the host target of Six6 remaining unidentified, we can only speculate as to how Six6 contributes to virulence of $F$. oxysporum f. sp. lycopersici on susceptible plants. The localization of GFP-tagged Six6 in the nucleus and cytoplasm of $N$. benthamiana leaves upon transient expression suggests that the effector target could be localized in either or both of these subcellular compartments. It has been shown that I-2 activation requires Avr2 recognition in the nucleus (Ma et al. 2013) and nuclear-localized Six6 might interfere with this event, thereby suppressing I2CD. Yet, its capacity to suppress I2CD is insufficient to suppress $I-2$ function in tomato, because $I-2$ plants are resistant to SIX6-expressing F. oxysporum f. sp. lycopersici strains. However, I-2-mediated resistance to $F$. oxysporum $\mathrm{f}$. sp. lycopersici is not absolute and growth of the fungus in the xylem vessels of roots and stems of resistant plants is frequently observed (Elgersma et al. 1972; our unpublished results). Possibly, some of this fungal growth is due to partial, Six6-mediated suppression of I-2, implying that fungal growth of a SIX6 knockout on a resistant plant will be reduced. Unfortunately, the reduction of fungal biomass already observed upon infection of susceptible plants by the SIX6 knockouts (Fig. 4) prevented us from testing this hypothesis. This virulence phenotype on susceptible plants also suggests that Six6 has effects on host susceptibility other than (partial) suppression of I-2-mediated host responses.

Future work should include experiments aimed at identification of the Six6 host targets, to uncover how this effector contributes to virulence of $F$. oxysporum $\mathrm{f}$. sp. lycopersici toward tomato and suppression of I2CD in $N$. benthamiana. It will also be interesting to see whether the Six6 homologs found in other plant pathogens are also required for full pathogenicity.

\section{MATERIALS AND METHODS}

\section{Alignment.}

The Six6 protein alignment was performed with ClustalW and Seaview.

\section{Plant material and fungal and bacterial strains.}

Tomato 'C32' was used for the F. oxysporum f. sp. lycopersici inoculation assays and is susceptible to all $F$. oxysporum $\mathrm{f}$. $\mathrm{sp}$. lycopersici races (Kroon and Elgersma 1993). A. thaliana ecotype Col-0 was used for transformation and the disease assays with $V$. dahliae JR2 (provided by B. Thomma, WUR, Wageningen, The Netherlands), P. syringae pv. tomato DC3000 (Whalen et al. 1991), and Fo5176 (originally isolated by Queensland Plant Pathology Herbarium, Queensland Department of Primary Industries and Fisheries, Brisbane, Australia). All F. oxysporum f. sp. lycopersici gene-deletion lines were generated in a Fol007 background (provided by L. Davidse, France), a race 2 isolate nonpathogenic on tomato plants carrying $I-2$ or $I-3$.

Agroinfiltrations were performed using the disarmed Agrobacterium tumefaciens strain GV3101::pMP90 (Koncz and Schell 1986), A. tumefaciens-mediated transformation of F. oxysporum f. sp. lycopersici was done with the strain EHA105 (Hood et al. 1993) and, for Arabidopsis thaliana transformation, the strain Agl-0 was used (Lazo et al. 1991).

\section{RNA isolation and RT-PCR.}

Ten-day-old tomato seedlings were inoculated with Fol007, the SIX6 knockout strain, or the knockout strain complemented with SIX6 with the root-dip method (Wellmann 1939) and then potted in vermiculite (Agra-vermiculite; Eveleens, Aalsmeer, The Netherlands). At $10 \mathrm{dpi}$, the roots were cut below the hypocotyls, rinsed twice with water, and dried with tissues. The root samples were ground in liquid nitrogen. Total RNA from the samples was extracted with TRIzol LS reagent (Invitrogen, Life Technologies, Grand Island, NY, U.S.A.) and subsequently purified with RNeasy Mini kit (Qiagen, Düsseldorf, Germany). DNA was removed by on-column treatment with RNase-free 
DNase (Qiagen). cDNA was synthesized using the M-MulV reverse-transcriptase RNase $\mathrm{H}$ minus kit (Fermentas, Thermo Scientific, Pittsburgh PA, U.S.A.). Either primer pair FP1995/ FP1996 or FP2155/FP2156 (list of all primer sequences in Supplementary Table S3) were used to amplify SIX6 from cDNA. FEM1 was amplified using primer pair FP157/FP158.

To assess SIX6 expression of F. oxysporum f. sp. lycopersici grown in artificial medium, $0.5 \mathrm{ml}$ of Fol4287 (race 2) at $10^{7}$ spores/ml was added to $4.5 \mathrm{ml}$ of a 1-week-old tomato MSK8 cell culture grown in BY medium (Felix et al. 1991) or to $\mathrm{NO}_{3}$ medium $\left(100 \mathrm{mM} \mathrm{KNO}_{3}, 3 \%\right.$ sucrose, and $0.17 \%$ yeast nitrogen base without amino acids or ammonia). After $24 \mathrm{~h}$ of incubation at $22^{\circ} \mathrm{C}$, the material was harvested, washed two times with sterile water, and freeze dried. RT-PCR was performed as described above but DNase (Fermentas) treatment was executed before cDNA synthesis.

\section{Construction of the SIX6 knockout and complementation constructs.}

To generate a SIX6 gene deletion, a 1,328-bp upstream sequence (starting 36 bp $5^{\prime}$ of the SIX6 start codon) was amplified by PCR using primers FP1509 and FP1510, carrying either an XbaI or HindIII site. The PCR product was inserted into the binary vector pRW2h (Houterman et al. 2008) upstream of the hygromycine resistance cassette. An 836-bp fragment starting $124 \mathrm{bp}$ after the SIX6 start codon containing an internal BssHII site was amplified using the primers FP1511 and FP1512 and BssHII digested. The resulting 676-bp fragment was inserted into a $S t u \mathrm{I} / B s s \mathrm{HII}$-digested vector downstream of the Hygromycine cassette.

The complementation construct was generated using primers FP1727 carrying a BcuI (SpeI) linker and FP1728. PCR amplification resulted in a 1.9-kb fragment starting 1,023 bp upstream of the SIX6 start codon and ending $261 \mathrm{bp}$ downstream of the stop codon. The fragment was integrated into an XbaI/Eco147I (StuI)-digested pRW1p vector.

\section{Construction of binary vectors for agroinfiltration.}

SIX6 was PCR amplified from genomic DNA of Fol007 (race 2). Forward primer FP2423 generated a truncated SIX6 gene lacking the sequence encoding its signal peptide. To allow C-terminal tagging of Six6, a PCR amplification was also done with the FP2204 reverse primer that removes the stop codon. To generate a similar fragment for $S I X 8$, the gene was amplified using primers FP2838 and FP2206 from cDNA isolated from Fol007-infected tomato roots. AVRl lacking the sequence encoding its signal peptide and prodomain was obtained by PCR amplification using primers FP2292 and FP2202 on cDNA of Fol001 (race 1)-infected tomato roots. To all PCR products, Gateway attB flanks were added in a subsequent PCR amplification with primers FP872 and FP873. The obtained attB PCR products were recombined via entry clone pDONR207 (Invitrogen) into binary vectors CTAPi (Rohila et al. 2004) and pGWB451 following the Gateway protocol (Invitrogen). All primers were purchased from MWG (Ebersgerg, Germany). $A V R 2$ - and I-2-carrying constructs have been described previously (Houterman et al. 2009; van Ooijen et al. 2008).

\section{Agroinfiltration of $N$. benthamiana.}

Agroinfiltrations were performed according (Ma et al. 2012) as described. In brief, A. tumefaciens strain GV3101 carrying the construct of interest was grown until an optical density at $600 \mathrm{~nm}\left(\mathrm{OD}_{600}\right)$ of 0.8 in $\mathrm{LB}_{\text {tum }}$ (tryptone at $10 \mathrm{~g} \mathrm{liter}^{-1}$, yeast extract at $5 \mathrm{~g} \mathrm{liter}^{-1}$, and $\mathrm{NaCl}$ at $2.5 \mathrm{~g} \mathrm{liter}^{-1}$ ) medium supplemented with $20 \mu \mathrm{M}$ acetosyringone and $10 \mathrm{mM}$ morpholinoethanesulfonic acid (MES), $\mathrm{pH}$ 5.6. The cells were resuspended in infiltration medium (Murashige-Skoog [MS] salts at $5 \mathrm{~g} / \mathrm{liter}$, sucrose at $20 \mathrm{~g} / \mathrm{liter}, 200 \mu \mathrm{M}$ acetosyringone, and $10 \mathrm{mM}$ MES, $\mathrm{pH}$ 5.6) to a final $\mathrm{OD}_{600}$ of 1.0 when used for in planta protein expression or localization studies. For suppression assays, Agrobacterium tumefaciens suspensions were diluted to an $\mathrm{OD}_{600}$ of 0.5 or 0.3 .

\section{Protein extraction and Western blotting.}

To determine accumulation of GFP- or TAPi-tagged recombinant proteins, agroinfiltrated $N$. benthamiana leaves were harvested 24 to $48 \mathrm{hpi}$ and frozen in liquid nitrogen. Protein extraction was done as described previously (Ma et al. 2012; van Ooijen et al. 2008) and $0.5 \mathrm{~g}$ of frozen plant tissue was ground in liquid nitrogen and allowed to thaw slowly in $1 \mathrm{ml}$ of extraction buffer ( $25 \mathrm{mM}$ Tris [pH 7.5], $1 \mathrm{mM}$ EDTA, 150 $\mathrm{mM} \mathrm{NaCl}, 5 \mathrm{mM}$ dithiothreitol, $1 \times$ Roche Complete protease inhibitor cocktail, $2 \%$ polyvinyl-polypyrrolidone, and $0.1 \%$ NP-40). The extract was centrifuged at $13,000 \mathrm{rpm}$ at $4^{\circ} \mathrm{C}$ for $30 \mathrm{~min}$ and the supernatant was filtered through Miracloth (Calbiochem, San Diego, CA, U.S.A.). The protein concentration was determined by measuring the $\mathrm{OD}_{280}$ on a spectrophotometer (Hitachi U-2900) and equal amounts of protein were loaded on a $12 \%$ sodium dodecyl sulfate (SDS) polyacrylamide gel. For protein detection, proteins were wet blotted on polyvinylidene diflouride membranes and equal loading and transfer were confirmed by staining the blot with $2 \%$ Ponceau $\mathrm{S}$ in $5 \%$ acetic acid. Subsequently, membranes were blocked with $5 \%$ milk in Tris-buffered saline and GFP or TAPi tag fusion proteins were detected with an anti-GFP (VXA6455; Invitrogen) (1:3,000 diluted) or anti-PAP antibody (Sigma $\mathrm{P} 1291)(1: 5,000$ diluted), which is linked to horseradish peroxidase. In case of GFP detection, a goat-antirabbit antibody (Pierce P31430) (1:8,000 diluted) was used as secondary antibody. In either case, the signal was detected using enhanced chemiluminescence (ECL Plus Western Blotting Detection System; GE Healthcare, Piscataway, NJ, U.S.A.)

\section{Confocal microscopy.}

In planta accumulation of Six6-GFP after agroinfiltration was visualized using confocal microscopy (Zeiss LSM 510). An Ar-laser (intensity set at 22\%) was used for excitation at $488 \mathrm{~nm}$. Fluorescence was detected with a 520- to 550-nmband path filter for GFP and autofluorescence of the plant tissue was recorded using a 650-nm-long path filter. Scans were taken with the C-Apochromat 40X1.2 Wcorr objective.

\section{Visualization and quantification of the HR.}

For quantification of cell death, three leaf discs with a diameter of $7 \mathrm{~mm}$ were collected per agroinfiltrated sector $27 \mathrm{~h}$ after agroinfiltration. The leaf discs were washed in $50 \mathrm{ml}$ of water for $30 \mathrm{~min}$ while shaking at $100 \mathrm{rpm}$. Afterward, the discs were placed with their abaxial sides facing downward in a well containing $3 \mathrm{ml}$ of $0.01 \%$ Silwet-L77. The leaf discs were vacuum infiltrated and the 12-well culture plates (Greiner) were incubated at room temperature under fluorescent lamps (25 lux) while shaking at $100 \mathrm{rpm}$. The solution $(25 \mu \mathrm{l})$ was sampled every 1 to $2 \mathrm{~h}$ for $12 \mathrm{~h}$ and conductivity was determined with a TwinCond conductivity meter (Horiba, Kyoto, Japan).

To visualize cell death, leaves were stained with trypan blue (Ma et al. 2012). Then, $50 \mathrm{ml}$ of staining solution $(100 \mathrm{ml}$ of lactic acid [DL Sigma L-1250], $100 \mathrm{~g}$ of phenol, $100 \mathrm{ml}$ of glycerol, $100 \mathrm{ml}$ of $\mathrm{H}_{2} \mathrm{O}$, and $100 \mathrm{mg}$ trypan blue) was mixed with $50 \mathrm{ml}$ of $96 \% \mathrm{EtOH}$ and heated in a water bath until boiling. Up to three leaves were added together to the boiling solution and allowed to stain for $5 \mathrm{~min}$. Leaves were distained with chloral hydrate solution at $2.5 \mathrm{mg} / \mathrm{ml}$ overnight and scanned using an Perfection 1200 Scanner (Epson, Long Beach, CA, U.S.A.). 


\section{A. tumefaciens growth curves.}

A. tumefaciens growth curves were measured as described (Hann and Rathjen 2007). A. tumefaciens GV3101 carrying the appropriate constructs was agroinfiltrated at an $\mathrm{OD}_{600}$ of 0.05. Two leaf discs were harvested from each agroinfiltrated area 0,2 , or $4 \mathrm{dpi}$. Bacteria were extracted in $500 \mu \mathrm{l}$ of $10 \mathrm{mM}$ $\mathrm{MgSO}_{4}$ after homogenizing the leaf material by adding two metal beads $(2.5 \mathrm{~mm}$ in diameter $)$ and placing the tube for 2.5 min in a paint shaker (Fast and Fluid management; IDEX Corporation, Lake Forest, IL, U.S.A.). Serial dilutions of the homogenate were made and $20 \mu \mathrm{l}$ of each dilution (typically $10^{-3}, 10^{-4}$, and $10^{-5}$ ) was plated on $\mathrm{LB}_{\text {tum }}$ supplemented with rifampicin $(20 \mu \mathrm{g} / \mathrm{ml})$. After 2 days of incubation at room temperature, the $\mathrm{CFU}$ were counted and the $\mathrm{CFU} / \mathrm{cm}^{2}$ value was calculated. Each sampling was performed in three technical and five biological replicates. Significance was tested with a paired student $t$ test $(P<0.05)$.

\section{Plant inoculations.}

Ten-day-old tomato seedlings were uprooted from the soil. The seedlings were placed for $5 \mathrm{~min}$ in a 5 -day-old $F$. oxysporum f. sp. lycopersici spore suspension $\left(10^{7}\right.$ spores $\left./ \mathrm{ml}\right)$ and potted. Disease progression was evaluated after 3 weeks. Plant weight and disease index (Rep et al. 2004) were scored for 20 plants/treatment. Significant differences between treatments were tested using ANOVA.

Inoculation of Arabidopsis thaliana plants with $V$. dahliae JR2 and scoring of the disease index was done as described (Yadeta et al. 2011). A. thaliana was grown under short-day conditions in a climate chamber $\left(21^{\circ} \mathrm{C}, 70 \%\right.$ relative humidity, and 11-h photoperiod). After 21 days, the plants were carefully removed from the soil and the roots were placed in a $V$. dahliae spore suspension $\left(10^{6}\right.$ spores $\left./ \mathrm{ml}\right)$ for $5 \mathrm{~min}$. Thereafter, the plants were transferred to fresh soil. After 2 to 3 weeks, the first disease symptoms developed. Disease symptoms were scored visually by measuring the size of the plants and evaluating development of chlorosis on the leaves (Yadeta et al. 2011).

The spore suspension $\left(5 \mathrm{ml}\right.$ at $10^{6}$ spores $\left./ \mathrm{ml}\right)$ of an $F$. oxysporum Fo5176 culture was added directly to the soil of 13day-old $A$. thaliana seedlings growing on a soil/sand mix (ratio $1: 1$ ). The disease index was scored (on a scale of $0=$ no disease symptoms; $1=$ one or two leaves with yellow vessels; $2=$ lowest full developed leaves show chlorosis; $3=$ all full developed leaves show chlorosis; $4=$ all leaves show chlorosis, including the rosette of new developed leaves; and $5=$ plant is dead) at 9 and 15 dpi.

$P$. syringae was cultured overnight in King's B medium (King et al. 1954) and resuspended in $10 \mathrm{mM} \mathrm{MgSO}_{4}$ to a final $\mathrm{OD}_{600}$ of 0.0007 . The bacteria were syringe infiltrated into the leaves of 22-day-old $A$. thaliana plants. At 3 dpi, leaf discs $(0.5 \mathrm{~cm})$ were collected and the bacteria were extracted in 10 $\mathrm{mM} \mathrm{MgSO}$. Different dilutions (typically $10^{-3}, 10^{-4}$, and $10^{-5}$ ) of the bacteria suspension were plated on King's B.

\section{Transformation of $\boldsymbol{F}$. oxysporum f. sp. lycopersici, targeted deletion, and complementation of SIX6.}

Transformation of F. oxysporum f. sp. lycopersici was mediated by A. tumefaciens transformation (Takken et al. 2004). Spores of a 5-day-old $F$. oxysporum f. sp. lycopersici culture were isolated and resuspended in IM $(10 \mathrm{mM}$ glucose, $10 \mathrm{mM}$ $\mathrm{K}_{2} \mathrm{HPO}_{4}, 10 \mathrm{mM} \mathrm{KH} \mathrm{PO}_{4}, 2.5 \mathrm{mM} \mathrm{NaCl}, 4 \mathrm{mM}\left[\mathrm{NH}_{4}\right]_{2} \mathrm{SO}_{4}$, $0.7 \mathrm{mM} \mathrm{CaCl}, 2 \mathrm{mM} \mathrm{MgSO}_{4}, 9 \mu \mathrm{M} \mathrm{FeSO}_{4}, 0.5 \%$ [wt/vol] glycerol, and $40 \mathrm{mM}$ MES, pH 5.3) supplemented with 200 $\mu \mathrm{M}$ acetosyringone to a final concentration of $2 \times 10^{6}$ spores $/ \mathrm{ml}$. A. tumefaciens containing the binary vector of interest was grown for $24 \mathrm{~h}$ in $2 \times$ yeast extract and tryptone me- dium supplemented with the appropriate antibiotics. Then, the cells were resuspended in $10 \mathrm{ml}$ of IM to an $\mathrm{OD}_{600}$ of 0.45 and incubated for $6 \mathrm{~h}$ at $28^{\circ} \mathrm{C}$. Then, $2 \mathrm{ml}$ of each of the $F$. $o x y$ sporum f. sp. lycopersici and A. tumefaciens resuspensions were mixed and aliquots of $25 \mu \mathrm{l}$ were transferred to ME25 filters placed on co-cultivation plates (the same as IM but containing $5 \mathrm{mM}$ glucose) solidified with $1.5 \%$ Bacto agar. After 2 days of incubation at $25^{\circ} \mathrm{C}$, the filters were transferred to Czapek Dox agar containing cefotaxime and hygromycin or zeocin (both $100 \mu \mathrm{g} / \mathrm{ml}$ ). Plates containing with zeocin were buffered with $0.1 \mathrm{M}$ Tris, $\mathrm{pH}$ 8.0. Putative transformants appeared after 2 to 4 days and monospores were made for further analysis. Absence of SIX6 in hygromycin-resistant transformants was tested using primer pair FP1490/FP1491. In locus insertion of the knockout cassette was confirmed by PCR using primer pairs FP745/FP2264 (right border) and FP2266/FP659 (left border). Presence of SIX6 in the SIX6 knockout complementation strains was also confirmed by PCR using three primer pairs, of which one (FP745/FP1961) amplified the region upstream of SIX6 and a part of the SIX6 coding region and the other two primer sets (FP1995/FP2218 and FP1959/FP746) amplified the region downstream of SIX6 and a part of the SIX6 coding region.

Transformation of $\boldsymbol{A}$. thaliana using the floral dip method.

A. thaliana plants were grown in a 12 -h photoperiod at $70 \%$ relative humidity and $21{ }^{\circ} \mathrm{C}$. The first inflorescence was removed to boost flower production. Agrobacterium tumefaciens carrying the dSPSIX6-TAP $i$ was grown in $250 \mathrm{ml}$ of $\mathrm{LB}_{\text {tum }}$ supplemented with spectinomycin $(100 \mu \mathrm{g} / \mathrm{ml})$ overnight. The bacteria were resuspended in $5 \%$ sucrose to a final $\mathrm{OD}_{600}$ of 0.8 and $0.02 \%$ Silwet was added. The flowers were dipped in the bacterial suspension, wrapped in plastic foil to increase humidity, and protected against direct light. The dipping was repeated after 1 week. After seed harvest and sterilization, the seed were plated on MA plates (MS including Gamborg B5 vitamins, at $2.2 \mathrm{~g} / \mathrm{liter}$ FeNaEDTA at $36.7 \mathrm{mg} / \mathrm{liter}$; MES [pH $5.8]$ at $1 \mathrm{~g} /$ liter; and $0.7 \%$ Daishin agar) containing nystatin at $100 \mu \mathrm{g} / \mathrm{ml}$ and phosphinothricin at $10 \mu \mathrm{g} / \mathrm{ml}$. Resistant plants were propagated and homozygous plant lines carrying single SIX6 T-DNA insertions were selected after segregation analysis. Six6 protein expression was analyzed by extracting the proteins from leaf material $(100 \mathrm{mg})$ in urea buffer $(9.5 \mathrm{M}$ urea, $100 \mathrm{mM}$ Tris [pH 6.8], $2 \%$ SDS, and $2 \% \beta$-mercaptoethanol) following detection of their attached TAPi tag by Western blot analysis.

\section{ACKNOWLEDGMENTS}

We thank T. Drost for assisting with the Pseudomonas and Agrobacterium bioassays; T. Hendrix, $\mathrm{H}$. Lemereis, and L. Tikovsky for greenhouse management; and A. Pietraszewska and R. Breedijk for assistance with fluorescence microscopy. F. Gawehns and F. L. W. Takken were supported by the Centre for BioSystems Genomics, a Netherlands Genomics Initiative; a Vici grant from The Netherlands Organization for Scientific Research funds supported M. Rep; Utopa foundation supported C. B. Michielse; and the University of Amsterdam supported P. M. Houterman, F. Ait Ichou, M. Hijdra, and F. L. W. Takken.

\section{LITERATURE CITED}

Abramovitch, R. B., Janjusevic, R., Stebbins, C. E., and Martin, G. B. 2006. Type III effector AvrPtoB requires intrinsic E3 ubiquitin ligase activity to suppress plant cell death and immunity. Proc. Natl. Acad. Sci. U.S.A. 103:2851-2856.

Agrios, G. N. 1997. Plant Pathology, 4th ed. Academic Press, San Diego, CA, U.S.A.

Armstrong, G. M., and Armstrong, J. K. 1981. Formae Speciales and Races of Fusarium oxysporum Causing Wilt Diseases. Penn State Uni- 
versity Press, University Park, PA, U.S.A.

Beckmann, C. H. 2000. Phenolic-storing cells: Keys to programmed cell death and periderm formation in wilt disease resistance and in general defence responses in plants? Physiol. Mol. Plant. Pathol. 57:101-110.

Chakrabarti, A., Rep, M., Wang, B., Ashton, A., Dodds, P. N., and Ellis, J. G. 2011. Variation in potential effector genes distinguishing Australian and non-Australian isolates of the cotton wilt pathogen Fusarium oxysporum f. sp. vasinfectum. Plant Pathol. 60:232-243.

Coll, N. S., Epple, P., and Dangl, J. L. 2011. Programmed cell death in the plant immune system. Cell Death Differ. 18:1247-1256.

Dou, D., Kale, S. D., Wang, X., Chen, Y., Wang, Q., Jiang, R. H., Arredondo, F. D., Anderson, R. G., Thakur, P. B., McDowell, J. M., Wang, Y., and Tyler, B. M. 2008. Conserved C-terminal motifs required for avirulence and suppression of cell death by Phytophthora sojae effector Avr1b. Plant Cell 20:1118-1133.

Elgersma, D. M., MacHardy, W. E., and Beckman, C. H. 1972. Growth and distribution of Fusarium oxysporum f. sp. lycopersici in nearisogenic lines of tomato resistant or susceptible to wilt. Phytopathology 62:1232-1237.

Felix, G., Grosskopf, D. G., Regenass, M., Basse, C. W., and Boller, T. 1991. Elicitor-induced ethylene biosynthesis in tomato cells: Characterization and use as a bioassay for elicitor action. Plant Physiol. 97:1925.

Gan, P., Ikeda, K., Irieda, H., Narusaka, M., O’Connell, R. J., Narusaka, Y., Takano, Y., Kubo, Y., and Shirasu, K. 2013. Comparative genomic and transcriptomic analyses reveal the hemibiotrophic stage shift of Colletotrichum fungi. New Phytol. 197:1236-1249.

Gilroy, E. M., Taylor, R. M., Hein, I., Boevink, P., Sadanandom, A., and Birch, P. R. 2011. CMPG1-dependent cell death follows perception of diverse pathogen elicitors at the host plasma membrane and is suppressed by Phytophthora infestans RXLR effector AVR3a. New Phytol. 190:653-666.

Guo, M., Tian, F., Wamboldt, Y., and Alfano, J. R. 2009. The majority of the type III effector inventory of Pseudomonas syringae pv. tomato DC3000 can suppress plant immunity. Mol. Plant-Microbe Interact. 22:1069-1080.

Hann, D. R., and Rathjen, J. P. 2007. Early events in the pathogenicity of Pseudomonas syringae on Nicotiana benthamiana. Plant J. 49:607-618.

Hogenhout, S. A., Van der Hoorn, R. A., Terauchi, R., and Kamoun, S. 2009. Emerging concepts in effector biology of plant-associated organisms. Mol. Plant-Microbe Interact. 22:115-122.

Hood, E. E., Gelvin, S. B., Melchers, L. S., and Hoekema, A. 1993. New Agrobacterium helper plasmid for gene transfer to plants. Transgen. Res. 2:208-218.

Houterman, P. M., Speijer, D., Dekker, H. L., de Koster, C. G., Cornelissen, B. J. C., and Rep, M. 2007. The mixed xylem sap proteome of Fusarium oxysporum-infected tomato plants. Mol. Plant Pathol. 8:215-221.

Houterman, P. M., Cornelissen, B. J., and Rep, M. 2008. Suppression of plant resistance gene-based immunity by a fungal effector. PLoS Pathog. 4:e1000061.

Houterman, P. M., Ma, L., van Ooijen, G., de Vroomen, M. J., Cornelissen, B. J., Takken, F. L., and Rep, M. 2009. The effector protein Avr2 of the xylem-colonizing fungus Fusarium oxysporum activates the tomato resistance protein I-2 intracellularly. Plant J. 58:970-978.

Jamir, Y., Guo, M., Oh, H. S., Petnicki-Ocwieja, T., Chen, S., Tang, X., Dickman, M. B., Collmer, A., and Alfano, J. R. 2004. Identification of Pseudomonas syringae type III effectors that can suppress programmed cell death in plants and yeast. Plant J. 37:554-565.

Jones, J. D., and Dangl, J. L. 2006. The plant immune system. Nature 444:323-329.

Katan, T. 1999. Current status of vegetative compatability groups in Fusarium oxysporum. Phytoparasitica 27:51-64.

Katan, T., and Di Primo, P. 1999. Current status of vegetative compatibility groups of Fusarium oxysporum: Supplement. Phytoparasitica 27:273-277

Kelley, B. S., Lee, S. J., Damasceno, C. M., Chakravarthy, S., Kim, B. D., Martin, G. B., and Rose, J. K. 2010. A secreted effector protein (SNE1) from Phytophthora infestans is a broadly acting suppressor of programmed cell death. Plant J. 62:357-366.

King, E. O., Ward, M. K., and Raney, D. E. 1954. Two simple media for the demonstration of pyocyanin and fluorescin. J. Lab. Clin. Med. 44:301-307.

Kleemann, J., Rincon-Rivera, L. J., Takahara, H., Neumann, U., Ver Loren van Themaat, E., van der Does, H. C., Hacquard, S., Stuber, K., Will, I., Schmalenbach, W., Schmelzer, E., and O'Connell, R. J. 2012. Sequential delivery of host-induced virulence effectors by appressoria and intracellular hyphae of the phytopathogen Colletotrichum higginsianum. PLoS Pathog. 8:e1002643.

Koncz, C., and Schell, J. 1986. The promoter of TI-DNA gene 5 controls the tissue-specific expression of chimeric genes carried by a novel type of Agrobacterium binary vector. Mol. Gen. Genet. 204:383-396.

Kroon, B. A. M., and Elgersma, D. M. 1993. Interactions between race 2 of Fusarium oxysporum f. sp. lycopersici and near-isogenic resistant and susceptible lines of intact plants or callus of tomato 58731 F71 137. J. Phytopathol. 137:1-9.

Lazo, G. R., Stein, P. A., and Ludwig, R. A. 1991. A DNA transformationcompetent Arabidopsis genomic library in Agrobacterium. Bio/Technology 9:963-967.

Lievens, B., Houterman, P. M., and Rep, M. 2009. Effector gene screening allows unambiguous identification of Fusarium oxysporum f. sp. lycopersici races and discrimination from other formae speciales. FEMS (Fed. Eur. Microbiol. Soc.) Microbiol. Lett. 300:201-215.

Ma, L. J., van der Does, H. C., Borkovich, K. A., Coleman, J. J., Daboussi, M. J., Di Pietro, A., Dufresne, M., Freitag, M., Grabherr, M., Henrissat, B., Houterman, P. M., Kang, S., Shim, W. B., Woloshuk, C., Xie, X., Xu, J. R., Antoniw, J., Baker, S. E., Bluhm, B. H., Breakspear, A., Brown, D. W., Butchko, R. A., Chapman, S., Coulson, R., Coutinho, P. M., Danchin, E. G., Diener, A., Gale, L. R., Gardiner, D. M., Goff, S., Hammond-Kosack, K. E., Hilburn, K., Hua-Van, A., Jonkers, W., Kazan, K., Kodira, C. D., Koehrsen, M., Kumar, L., Lee, Y. H., Li, L., Manners, J. M., Miranda-Saavedra, D., Mukherjee, M., Park, G., Park, J., Park, S. Y., Proctor, R. H., Regev, A., Ruiz-Roldan, M. C., Sain, D., Sakthikumar, S., Sykes, S., Schwartz, D. C., Turgeon, B. G., Wapinski, I., Yoder, O. Young, S., Zeng, Q., Zhou, S., Galagan, J., Cuomo, C. A., Kistler, H. C., and Rep, M. 2010. Comparative genomics reveals mobile pathogenicity chromosomes in Fusarium. Nature 464:367-373.

Ma, L., Lukasik, E., Gawehns, F., and Takken, F. L. 2012. The use of agroinfiltration for transient expression of plant resistance and fungal effector proteins in Nicotiana benthamiana leaves. Methods Mol. Biol. 835:61-74.

Ma, L., Cornelissen, B. J., and Takken, F. L. 2013. A nuclear localization for Avr2 from Fusarium oxysporum is required to activate the tomato resistance protein I-2. Front. Plant Sci. 4:94.

Michielse, C. B., van Wijk, R., Reijnen, L., Manders, E. M., Boas, S., Olivain, C., Alabouvette, C., and Rep, M. 2009. The nuclear protein Sge1 of Fusarium oxysporum is required for parasitic growth. PLoS Pathog. 5:e1000637.

Petersen, T. N., Brunak, S., von Heijne, G., and Nielsen, H. 2011. SignalP 4.0: Discriminating signal peptides from transmembrane regions. Nat. Methods 8:785-786.

Postma, W. J., Slootweg, E. J., Rehman, S., Finkers-Tomczak, A., Tytgat, T. O., van Gelderen, K., Lozano-Torres, J. L., Roosien, J., Pomp, R., van Schaik, C., Bakker, J., Goverse, A., and Smant, G. 2012. The effector SPRYSEC-19 of Globodera rostochiensis suppresses CC-NB-LRRmediated disease resistance in plants. Plant Physiol. 160:944-954.

Rep, M. 2005. Small proteins of plant-pathogenic fungi secreted during host colonization. FEMS (Fed. Eur. Microbiol. Soc.) Microbiol. Lett. 253:19-27.

Rep, M., van der Does, H. C., Meijer, M., van Wijk, R., Houterman, P. M., Dekker, H. L., de Koster, C. G., and Cornelissen, B. J. 2004. A small, cysteine-rich protein secreted by Fusarium oxysporum during colonization of xylem vessels is required for I-3-mediated resistance in tomato. Mol. Microbiol. 53:1373-1383.

Rep, M., Meijer, M., Houterman, P. M., van der Does, H. C., and Cornelissen, B. J. 2005. Fusarium oxysporum evades I-3-mediated resistance without altering the matching avirulence gene. Mol. PlantMicrobe Interact. 18:15-23.

Rohila, J. S., Chen, M., Cerny, R., and Fromm, M. E. 2004. Improved tandem affinity purification tag and methods for isolation of protein heterocomplexes from plants. Plant J. 38:172-181.

Schmidt, S. M., Houterman, P. M., Schreiver, I., Ma, L., Amyotte, S., Chellappan, B., Boeren, S., Takken, F. L., and Rep, M. 2013. MITEs in the promoters of effector genes allow prediction of novel virulence genes in Fusarium oxysporum. BMC Genomics 14:119.

Stassen, J. H., and Van den Ackerveken, G. 2011. How do oomycete effectors interfere with plant life? Curr. Opin. Plant Biol. 14:407-414.

Takken, F. L., Van Wijk, R., Michielse, C. B., Houterman, P. M., Ram, A. F., and Cornelissen, B. J. 2004. A one-step method to convert vectors into binary vectors suited for Agrobacterium-mediated transformation. Curr. Genet. 45:242-248.

Thatcher, L. F., Gardiner, D. M., Kazan, K., and Manners, J. M. 2012. A highly conserved effector in Fusarium oxysporum is required for full virulence on Arabidopsis. Mol. Plant-Microbe Interact. 25:180-190.

Thomma, B. P., Nurnberger, T., and Joosten, M. H. 2011. Of PAMPs and effectors: The blurred PTI-ETI dichotomy. Plant Cell 23:4-15.

Tjamos, E. C., and Beckman, C. H. 1989. Vascular Wilt Diseases of Plants: Basic Studies and Control. Springer-Verlag, Berlin.

van Ooijen, G., Mayr, G., Kasiem, M. M., Albrecht, M., Cornelissen, B. J., and Takken, F. L. 2008. Structure-function analysis of the NB-ARC domain of plant disease resistance proteins. J. Exp. Bot. 59:1383-1397. 
Wang, Q., Han, C., Ferreira, A. O., Yu, X., Ye, W., Tripathy, S., Kale, S. D., Gu, B., Sheng, Y., Sui, Y., Wang, X., Zhang, Z., Cheng, B., Dong, S., Shan, W., Zheng, X., Dou, D., Tyler, B. M., and Wang, Y. 2011. Transcriptional programming and functional interactions within the Phytophthora sojae RXLR effector repertoire. Plant Cell 23:20642086.

Wellmann, F. L. 1939. A technique for studying host resistance and pathogenicity in tomato Fusarium wilt. Phytopathology 29:945-956.

Whalen, M. C., Innes, R. W., Bent, A. F., and Staskawicz, B. J. 1991. Identification of Pseudomonas syringae pathogens of Arabidopsis and a bacterial locus determining avirulence on both Arabidopsis and soybean. Plant Cell 3:49-59.

Wilkins, M. R., Gasteiger, E., Bairoch, A., Sanchez, J. C., Williams, K. L., Appel, R. D., and Hochstrasser, D. F. 1999. Protein identification and analysis tools in the ExPASy server. Methods Mol. Biol. 112:531-552.

Win, J., Chaparro-Garcia, A., Belhaj, K., Saunders, D. G., Yoshida, K., Dong, S., Schornack, S., Zipfel, C., Robatzek, S., Hogenhout, S. A., and Kamoun, S. 2012. Effector biology of plant-associated organisms: Con- cepts and perspectives. Cold Spring Harb. Symp. Quant. Biol. 77:235247.

Yadeta, K. A., Hanemian, M., Smit, P., Hiemstra, J. A., Pereira, A., Marco, Y., and Thomma, B. P. 2011. The Arabidopsis thaliana DNA-binding protein AHL19 mediates Verticillium wilt resistance. Mol. PlantMicrobe Interact. 24:1582-1591.

Yoshino, K., Irieda, H., Sugimoto, F., Yoshioka, H., Okuno, T., and Takano, Y. 2012. Cell death of Nicotiana benthamiana is induced by secreted protein NIS1 of Colletotrichum orbiculare and is suppressed by a homologue of CgDN3. Mol. Plant-Microbe Interact. 25:625-636.

\section{AUTHOR-RECOMMENDED INTERNET RESOURCES}

ClustalW database: www.ebi.ac.uk/Tools/msa/clustalw2

Seaview, a multiplatform, graphical user interface for multiple sequence alignment and molecular phylogeny:

pbil.univ-lyon1.fr/software/seaview.html 